\title{
Economic crisis, unemployment and illegal drug consumption in Spain
}

\author{
Bruno Casal, Berta Rivera and Luis Currais \\ Department of Economics and Financial Accounting, \\ University of A Coruña, A Coruña, Spain
}

Illegal drug consumption in Spain

Received 30 July 2019 Revised 4 November 2019 11 February 2020 Accepted 27 February 2020

\begin{abstract}
Purpose - The purpose of this paper is to analyse the association between drug consumption and unemployment. This paper also studies the differential association between these variables in both the preand current-crisis periods. The results are compared in an attempt to verify that the population of users is more vulnerable in terms of how likely they are to get and hold down a job in the labour market.

Design/methodology/approach - Matching methods and microdata from the Survey on Alcohol and Drugs in Spain, EDADES are used. The use of these methods on the estimates carried out prove to be particularly effective in reducing treatment-selection bias. The authors' interest is also to analyse the differential association between the interest variables in both the pre- and current-crisis periods. For this purpose, the authors also use the differences-in-differences (DID) estimation method between the two periods to check if the impact of drug use on unemployment depends on the economic context. The estimations are compared in an attempt to verify that the population of users is less likely to attain and hold down a job in the labour market than non-drug users.

Findings - The results obtained in the current study are consistent with the hypothesis that drug use decreases an individual's capacity and availability when he or she is trying to enter the labour market. In both 2007 and 2013, drug users were more likely to be unemployed, regardless of the type of drug. Differences in the probability of being unemployed intensify during an economic crisis. In light of these results, it is possible to conclude that the negative effect of drug consumption on an individual's employability is increased during periods of economic recession.
\end{abstract}

Research limitations/implications - The study presented here has some limitations. Firstly, crosssectional data were used to examine the causal relationship between consumption and employment. In this sense, the results are susceptible to bias. The unavailability of longitudinal data on the same individual made it impossible for the researchers to consider periods of abstinence, the duration of periods of consumption and how this consumption affected an individual's productivity and his or her working situation. Another limitation is that certain relevant unemployment variables may have been omitted. Among the variables that affect an individual's labour participation is the existence of sources of income as an alternative to market salaries. With state subsidies, income from illegal activities and money sent by family or friends, an individual may decide not to work. This problem could be mitigated if omitted variables operate in a similar way throughout both of the periods examined.

Social implications - Given the results obtained in this paper, the authors believe that public policy conclusions should be mainly concerned with the importance of implementing proactive employment policies, along with family support programmes and a greater role for primary care among the people with the highest

(C) Bruno Casal, Berta Rivera and Luis Currais. Published in Applied Economic Analysis. Published by Emerald Publishing Limited. This article is published under the Creative Commons Attribution (CC BY 4.0) licence. Anyone may reproduce, distribute, translate and create derivative works of this article (for both commercial and non-commercial purposes), subject to full attribution to the original publication and authors. The full terms of this licence may be seen at http://creativecommons.org/ licences/by/4.0/legalcode

Funding for this study was provided by the Spanish Ministry of Science and Innovation, (Grant number ECO2013-48217).

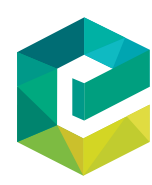

Applied Economic Analysis Vol. 28 No. 83, 2020 pp. $153-170$

pp. 153-170
Emerald Publishing Limited
$2632-7627$ DOI 10.1108/AEA-07-2019-0014 
AEA 28,83

risks of exclusion. Health treatment should go jointly with measures that make it easier for individuals to enter the workforce. These steps would only be possible with an improved level of education and more complete professional profiles, to increase motivation when individuals seek employment.

Originality/value - This study could make various contributions to the existing body of evidence. In the authors' knowledge, this is the first attempt to document the effect of the economic crisis on the employability of the drug-using population in contrast with the general population. Moreover, a methodology is presented that provides an alternative to those used in earlier studies, in terms of reducing treatment-selection bias. At the same time, the use of a DID estimation method between pre- and current-crisis periods allow us to check if the impact of drugs consumption on unemployment depends on the economic context.

Keywords Spain, Economic crisis, Unemployment, Drug consumption, Matching methods

Paper type Research paper

\section{Introduction}

Mental health problems are related to deprivation, poverty, inequality and other social and economic determinants of health (World Health Organization [WHO], 2009, 2011). The economic crisis experienced in most European countries since 2007 has impacted the factors that secure mental health, reducing public service budgets and affecting education and health care systems. The current economic crisis is mostly affecting low-income people and increasing the social exclusion of the most vulnerable groups, such as ethnic minorities, migrants, the unemployed and the older population (World Health Organization [WHO], 2009; Marmot and Bell, 2009). In this sense, economic crises generate high risk to the mental well-being of the people affected and their families. Along with the crisis, there is a reduction in the socio-economic scale that affects the social gradients of health existing in European countries (Wilkinson and Marmot, 2003). Previous evidence reveals that people experiencing unemployment and impoverishment, as well as those with family disorders, are at greater risk of mental health conditions, such as depression, alcohol use disorders and suicide (Skapinakis et al., 2006; World Health Organization [WHO], 2009; Economou et al., 2008; Jenkins et al., 2008; Chang et al., 2009; De Goeij et al., 2015; Dubanowicz and Lemmens, 2015). Among other determinants, unemployment appears to be a major driver of increased mental health problems during an economic crisis (Mathers and Schofield, 1998; Artazcoz et al., 2004; Stuckler et al., 2011; VA Hal, 2015; Nagelhout et al., 2017).

From 2007 onwards, the economic dynamics of Spain and other European countries have been characterised by a sharp fall in economic activity. The number of people out of work rose from just over 1.8 million in 2007, with an unemployment rate of 8.2 per cent, to 6.5 million in 2013, with an unemployment rate of 26.09 per cent. The only European Union (EU) country that exceeded these figures was Greece, whose unemployment rate was 27.5 per cent. Long-term unemployment trends were particularly alarming in Spain. In 2013, 12.5 per cent of the men and 13.5 per cent of the women were unemployed. These figures were well above the EU-28 averages (5.2 for men and 5.1 for women) (Instituto Nacional de Estadística [INE], 2014).

There is an extensive body of evidence describing how drug use and unemployment are associated. Recent research by Ayllón and Ferreira-Batista (2018) analyses changes in drug consumption patterns and attitudes towards drugs in relation to the youth unemployment rates caused by the Great Recession. This analysis is based on data from European countries. According to their findings, a 1 per cent increase in the regional unemployment rate can be associated with a 0.7 per cent rise in the ratio of young people who have ever consumed cannabis.

Several authors suggest that illicit drug use can negatively affect the productivity and labour market position of individuals (MacDonald and Pudney, 2000; French et al., 2001; Alexandre and French, 2004; Compton et al., 2014). Using data from the British Crime Survey, a household victimisation survey representative of the adult population of England 
and Wales, MacDonald and Pudney (2000) examine the effect of illicit drug use on two labour market outcomes: unemployment and occupational attainment. The drug use is separated into "hard" and "soft" categories, based on the common perception of differing risk between drugs. The authors find evidence to suggest that drug use, particularly the use of hard drugs (opiates, cocaine and crack cocaine), is associated with an increased risk of unemployment, regardless of age or gender.

French et al. (2001) estimate the probability of employment and labour force participation for illicit drug users among the US adult population. Results indicate that chronic drug use is significantly negatively related to employment status. In the same way, Alexandre and French (2004) analyse the effects of chronic drug use on employment in low-income and high-crime neighbourhoods in Miami, Florida. Results show that chronic drug use significantly reduces the probability of being employed. Finally, Compton et al. (2014) obtain similar findings when analysing data from 405,000 non-institutionalised adults between 2002 and 2010. The authors find a strong correlation between employment status and the problematic use of substances, including alcohol and drugs.

A systematic revision of the literature covering the impact of drug consumption on unemployment and vice versa between 1990 and 2010 (Henkel, 2011) focuses on the relationship between substance abuse and employment status, the effect of unemployment on drug treatments and the relationship between the business cycle, unemployment rate and substance use. Regarding the effects of substance use/abuse on employment, the author reviews 15 articles, of which 11 were written in the USA, 2 in Great Britain and 1 in Finland. Of these articles, six focus on the consumption of alcohol and three on alcohol and other substances. Five consider illicit drugs exclusively. One of the main findings of his review is that drug consumption negatively affects employment outcomes. On the one hand, problematic drug users are more likely to lose their job; on the other hand, they are less likely to find employment later on.

However, it is also possible to find empirical research supporting the premise that illicit drug use has neither significant nor positive effects on wages and labour market success (Kaestner, 1991; Gill and Michaels, 1992; Register and Williams, 1992; Buchmueller and Zuvekas, 1998; Van Ours, 2006). These studies suggest that this relationship mostly depends on the age of the individuals participating in the job market and the type of drug consumed. Kaestner (1991) explores the effects of cocaine and marijuana use on the wages of young adults in the USA. He considers the endogeneity of drug use in a wage equation implementing a two-stage least squares procedure and finds that illicit drug use does not have the expected negative effects on wages.

Likewise, Gill and Michaels (1992) evaluate the effects of drug use on wages and employment in the USA, using microdata from 1980 and 1984. According to their findings, illegal drug use negatively affects employment levels only when the sample of users of hard and soft drugs is considered. Nevertheless, if the analysed sample is only of hard drug users, the effect is insignificant. Register and Williams (1992) analyse the data on marijuana and cocaine use from the wave of 1984 from the same survey. The authors examine the hypothesis that drug use reduces labour market productivity. With reference to predicted marijuana use, they find that the probability of being employed declines as the extent of use increases. Regarding predicted cocaine use, the probability of employment is not significantly influenced by cocaine use. Buchmueller and Zuvekas (1998) assess the relationship between drug use and two labour market outcomes: income and employment. These authors distinguish between non-problematic (i.e. moderate) and problematic use of illicit drugs and analyse two cohorts of men (18-29 and 30-45 years old). The authors observe a negative relationship between problematic drug use and both income and employment. This relationship is somewhat weak for young workers. 
AEA

28,83
Finally, Van Ours (2006) considers the employment effects of cannabis and cocaine use among the inhabitants of Amsterdam. The data are based on self-reported information gathered from three surveys conducted during 1994, 1997 and 2001. Results obtained report no negative effects of drug use on the employment rate for females. For males, there is a negative correlation between past cannabis and cocaine use and employment. However, this negative effect does not occur after correcting for the effect of unobserved personal characteristics.

In Spain, Colell et al. (2015) analyse the changes in drug use before and during the economic crisis. Authors identify differences in the patterns of drug consumption between employed and unemployed individuals according to the type of drug, as well as the age and gender of the drug users. Changes in legal and illegal drug consumption as a response to the Great Recession in Spain are presented by Martín and Vall (2016). The authors analyse differences in unemployment rates across provinces to identify the effects of business cycle variation on drug consumption. They find a relation between worsening economic conditions and a marked increase in illegal drug consumption. Taking gender and employment status into account, Arroyo et al. (2019) look at how the economic downturn affects psychotropic drug consumption in Spain. Results suggest that employment probability stands out as a factor when explaining differences in the probability of consuming psychotropic drugs. Nevertheless, to our knowledge, there is no evidence analysing the causality effect of illegal drug use and unemployment in the Spanish context.

From a methodological perspective, it is necessary to be cautious when comparing results between studies. Inconsistent trends in the literature may be attributed to, among other factors, the specification of labour market outcomes and methods used to address the endogeneity of drug use. This potential endogeneity may come from a direct effect of income on drug consumption and from the relationships, not observed, in which individuals are related to labour market success (Buchmueller and Zuvekas, 1998).

In this research, we provide evidence for the negative impact of illegal drug consumption on employment. Although an association between both variables is already indicated, there is a great deal of debate surrounding the mechanism and direction of the causality of these effects. The present analysis contributes to the growing body of literature by incorporating matching methods based on microdata from the Survey on Alcohol and Drugs in Spain, EDADES (Observatorio Español sobre Drogras [OED], 2007, 2013). The use of these methods on the estimates carried out prove to be particularly effective in reducing treatment-selection bias. Our interest is also to analyse the differential association between the interest variables in both the pre- and current-crisis periods. For this purpose, we also use the differences-in-differences (DID) estimation method between the two periods to check if the impact of drug use on unemployment depends on the economic context. The estimations are compared in an attempt to verify that the population of users is less likely to attain and hold down a job in the labour market compared with non-drug users.

The remainder of the article is organised as follows. Section 2 describes the data and methodology used for the empirical analysis. The Sections 3 and 4 present the results and the main conclusions, respectively.

\section{Data and methodology}

\subsection{Data}

This study is based on microdata from the EDADES for 2007 and 2013 (Observatorio Español sobre Drogras [OED], 2007, 2013). The year 2007 can be considered the starting point for the current economic crisis while, in 2013, unemployment levels in Spain reached their highest point in that country's history. The EDADES survey is conducted every two years on the population residing in Spanish households, of the age group of 15-64 years. The 
survey's methodology is similar to that used in other countries in the EU and the USA. For descriptive purposes, international comparisons can, therefore, be consulted (Spanish Government Delegation for the National Plan on Drugs; Delegación del Gobierno para el Plan Nacional sobre Drogas [DGPNSD], 2015).

A total of 23,715 surveys were valid in 2007, and 23,136 in 2013. The selected sample was restricted to the working-age population (16-64 years) so that the final size of the surveys included 23,258 individuals in 2007 and 22,862 individuals in 2013. The variables used in the analysis were maintained along the same lines over the two years.

For the empirical analysis, the works of Buchmueller and Zuvekas (1998) or Kaestner (1991) are considered as a starting point. Relevant drug use explanatory variables to consider in the estimations and the comparison between drug users and non-users (in Kaestner, 1991), justify these studies as the main references to our analysis.

A set of variables that the literature shows to influence labour market outcomes, such as family composition, marital status and level of education, among other demographic variables, was selected. Other variables - included in the propensity score model - would be determined on the basis of their statistical significance and their overall influence on the outcome and treatment variables. Dummy variables also became effective in the analysis. These variables represented the region in which the individual resided.

Regional dummies were proxy variables for the availability of re-employment opportunities in the geographical area and the social policies implemented to reduce the adverse effects of drug consumption on employability (Urbanos-Garrido and Lopez-Valcarcel, 2015). Furthermore, the relationship between substance use and unemployment is likely to be influenced by the overall employment rate for the area (Khan et al., 2002; Ritter and Chalmers, 2011).

The study is limited to the consumption of cocaine and cannabis, given that these were the most widely used illegal substances in Spain at the time. For this reason, the inclusion in the sample of consumers of other substances whose prevalence was significantly lower would reduce the reliability of the results. According to the EDADES (2013), the illegal drugs with the highest prevalence of consumption in the past 12 months were cannabis (9.2 per cent) and cocaine ( 2.2 per cent). Also in the previous year, heroin consumption was low ( 0.1 per cent of the population), and for the same past 12 months, in the population aged 15 to 64 years, 0.7 per cent consumed ecstasy and 0.6 per cent consumed amphetamines. The prevalence of new psychoactive substances consumption was estimated at 0.7 per cent in the population aged 15 to 64 years. According to this report, cocaine and, more notably, cannabis are the preferred drug choices among frequent and high-risk users in Spain.

To verify the effect that consumption had on employment status, the consumption indicator considers whether the surveyed individual has used drugs in the year before the interview. Although the frequency of consumption was a critical factor for studying this relationship, the survey did not gather diagnostic data that would distinguish users by their degree of dependence. Poly-drug consumption increases the effects between drugs, reinforces addiction and hinders an individual's treatment (European Monitoring Centre for Drugs and Drug Addiction [EMCDDA], 2009). Therefore, the relationship between consuming a combination of illegal drugs and participating in the labour market was examined when individuals disclosed that they consumed cocaine and cannabis within the same time frame.

\subsection{Methodology}

To analyse the impact that consuming drugs had on unemployment, matching techniques were employed. With these techniques, causal effects could be estimated using observational (non-randomised) data, by obtaining treated and control groups with similar 
AEA

28,83

covariate distributions. This empirical strategy had been used in previous studies to analyse the association between health status and unemployment (Böckerman and Ilmakunnas, 2009; Urbanos-Garrido and Lopez-Valcarcel, 2015).

A matching method was employed, based on separate propensity scores for 2007 and 2013. Probit regressions are used in the first step of the model to estimate the probability of using illicit drugs in the past 12 months ("treated") as a function of the observable covariates vector $X$ associated with the treatment group for each year:

$$
P\left(D_{i}=1 \mid X\right)=\delta X_{i}+\varepsilon_{i s},
$$

considering $D i$ as a binary treatment indicator that presents the value of 1 if the individual $i$ receives treatment (drug use), and 0 if this is not the case.

Using the estimated coefficients on $X$, we calculated the propensity scores are calculated $\left(\rho=\gamma \hat{\chi}_{1}\right)$-the probability of consuming drugs, conditional on the characteristics $X_{i}$. Using the propensity scores, the effect of treatment on the treated (ATT) can be estimated using a kernel matching algorithm. Let $T$ and $C$ be the set of treated and control units, respectively, and $Y_{i}^{T}$ and $Y_{j}^{C}$ be the observed outcomes of the treated and control units, respectively. Then, the kernel matching estimator is given by:

$$
\tau^{k}=\frac{1}{N^{T}} \sum_{i \in T}\left\{Y_{i}^{T}-\frac{\sum_{j \in C} Y_{j}^{C} G\left(\frac{\rho_{j}-\rho_{i}}{h_{n}}\right)}{\sum_{k \in C} G\left(\frac{\rho_{k}-\rho_{i}}{h_{n}}\right)}\right\}
$$

where $N^{T}$ is the number of matched treated in the sample, $G(\cdot)$ is a kernel function, and $h_{n}$ is a bandwidth parameter.

$Y_{i}\left(D_{i}\right)$ denotes the potential outcome for each individual $i$ (=1 if unemployed, $=0$ if employed), where $i=1, \ldots, N$, and $N$ denotes the total population. The treatment effect of an individual $i$ can be written as:

$$
\mathrm{T}_{i}=Y_{i}(1)-Y_{i}(0)
$$

The parameter of interest is the $A T T$, defined as:

$$
\mathrm{T}_{A T T}=E(\mathrm{~T} \mid D=1)=E[Y(1) \mid D=1]-E[Y(0) \mid D=1]
$$

The term $E[Y(0) \mid D=1]$ was the counterfactual: what the labour status of an individual using illicit drugs would be if he/she did not use these substances. As the counterfactual mean for those being treated was not observed, to estimate the ATT, several assumptions needed to be made (Caliendo and Kopeinig, 2008). It was assumed that all the relevant differences between the treated and non-treated groups were captured in the $X$ vector. Moreover, it was necessary to exclude treated individuals with a probability of being treated larger than the largest probability (p) in the non-treated group.

Among the different matching algorithms, the results obtained by employing the kernel algorithm, with a normal distribution, were presented. The main advantage of this approach is the lower variance that is achieved because more information is used versus matching 
algorithms that only a few observations from the comparison group are used to construct the counterfactual outcome of a treated individual (Caliendo and Kopeinig, 2008). Nearestneighbour matching was also implemented, to compare the robustness of the results obtained.

To study whether the crisis changes the relationship between drug consumption and unemployment, the DID approach is implemented. This method allows us to estimate the effect of drugs use, by comparing changes in unemployment between 2007 and 2013. Controlling by $X$ covariates, the model includes the fixed parameter $\delta$ for the effect of drug use in the base year, and the parameter $\lambda$, for the change in employment after the crisis. The parameter $\gamma$ is the interaction between them; it measures the change in the effect of drug use on the employment status during the crisis compared to the effect in 2007 . We estimated the following equation:

$$
Y_{i d t}=\alpha+\delta \text { drug_use } e_{i t}+\lambda t+\gamma\left(\text { drug_use }_{i t} * t\right)+\beta_{t} X_{i t}+\epsilon_{i d t}
$$

where $t$ is equal to 1 , if the year is 2013 ( $t=0$ means 2007), and the subscript $d$ stands for drug use status.

All analyses were performed using STATA version 14 software (Stata Corp, 2015).

\section{Results}

Table I provides the descriptive statistics for the variables used in the propensity score models for each of the years considered. In terms of the labour market variable, it was possible to detect a 15.6 per cent increase in the number of individuals unemployed between 2007 and 2013.

Table II presents the descriptive statistics for employment variables in relation to the type of substance consumed. Frequencies are presented for the periods prior to and subsequent to the crisis. As can be seen, the percentage of those out of work among the substance users is higher during the crisis than it is in the period before. For all consumption categories, the unemployment rate increases between 2007 and 2013. The highest unemployment frequency (39.61 per cent) for cannabis and cocaine users occurs in 2013. In the same way, the percentage of those who are working but who also consume one of the related categories of drugs sharply decreases in the period from 2007 to 2013. It fell by nearly 20 percentage points in the case of cannabis and cannabis and cocaine use. In this regard, the negative effects of the economic crisis appear to affect the activity indicators for the individuals included in the survey sample.

Tables III and IV show the ATT obtained in the estimates for 2007 and 2013, taking into account differences from the covariate vector $X$ for the two subsamples - the estimated probit equations for propensity score are displayed in Table AI (Appendix). For each period, the first column presents the probability of being unemployed if drugs were consumed, while the second one shows the probability of being unemployed if the individual had not taken drugs (counterfactual). In the third column, one finds the impact of drug consumption on the working life of an individual in terms of the difference in the probability rate of being unemployed between treated (consuming) and non-treated groups (non-consuming).

For Table III, the results were obtained using the kernel matching method. With these techniques, a positive average effect, significantly distinct from zero, can be discerned. Thus, it can be affirmed that a "net" effect is felt on the unemployment situation of the drug consumers involved in the study. The coefficients obtained suggest that, for both 2007 and 2013, the likelihood of being unemployed is greater among drug users compared with nondrug users. 


\begin{tabular}{|c|c|c|c|c|}
\hline Main dimension & Variable & Definition & $\begin{array}{c}2007 \\
(N=23,258)\end{array}$ & $\begin{array}{c}2013 \\
(N=22,862)\end{array}$ \\
\hline Labour status & unemployed & $\begin{array}{l}1 \text { if the person claims to be } \\
\text { unemployed }\end{array}$ & $8.90 \%$ & $24.50 \%$ \\
\hline \multirow[t]{5}{*}{ Education } & educO & $\begin{array}{l}\text { Primary education or below } \\
\text { (reference category) }\end{array}$ & $21.30 \%$ & $13.85 \%$ \\
\hline & educ1 & Lower secondary education & $31.30 \%$ & $37.52 \%$ \\
\hline & educ2 & Upper secondary education & $28.28 \%$ & $29.92 \%$ \\
\hline & educ3 & Short-cycle, tertiary education & $9.53 \%$ & $8.26 \%$ \\
\hline & educ4 & Bachelors or equivalent & $9.59 \%$ & $10.46 \%$ \\
\hline \multirow[t]{4}{*}{ Marital status } & mstato & $\begin{array}{l}1 \text { if the person claims to be } \\
\text { single (reference category) }\end{array}$ & $42.31 \%$ & $46.6 \%$ \\
\hline & mstat1 & $\begin{array}{l}1 \text { if the person claims to be } \\
\text { married }\end{array}$ & $50.12 \%$ & $46.12 \%$ \\
\hline & mstat2 & $\begin{array}{l}1 \text { if the person claims to be } \\
\text { separated/divorced }\end{array}$ & $5.04 \%$ & $5.75 \%$ \\
\hline & mstat3 & $\begin{array}{l}1 \text { if the person claims to be } \\
\text { widowed }\end{array}$ & $2.52 \%$ & $1.52 \%$ \\
\hline Sex & male & 1 if male & $46.56 \%$ & $50.86 \%$ \\
\hline Age & age & Age in years & $37.49(0.088)$ & $36.90(0.083)$ \\
\hline Home & home & $\begin{array}{l}\text { People living in the same } \\
\text { home }\end{array}$ & $3.08(0.08)$ & $3.01(0.008)$ \\
\hline Nationality & foreigner & 1 if the person is a foreigner & $13.00 \%$ & $13.00 \%$ \\
\hline Cannabis & cann_pastyear & Used in the past year & $10.53 \%$ & $10.44 \%$ \\
\hline Cocaine & coc_pastyear & Used in the past year & $3.00 \%$ & $2.35 \%$ \\
\hline Cannabis and Cocaine & cocandcann_pastyear & Used in the past year & $2.50 \%$ & $1.83 \%$ \\
\hline \multirow[t]{17}{*}{ Region } & rego & Andalucia (reference category) & $9.32 \%$ & $9.34 \%$ \\
\hline & reg1 & Aragon & $3.80 \%$ & $3.71 \%$ \\
\hline & reg2 & Asturias & $3.58 \%$ & $3.34 \%$ \\
\hline & reg3 & Baleares & $3.85 \%$ & $3.52 \%$ \\
\hline & reg4 & Canarias & $10.78 \%$ & $8.21 \%$ \\
\hline & reg5 & Cantabria & $3.77 \%$ & $4.18 \%$ \\
\hline & $\operatorname{reg} 6$ & Castilla y León & $5.25 \%$ & $5.11 \%$ \\
\hline & $\operatorname{reg} 7$ & Castilla-La Mancha & $4.54 \%$ & $6.88 \%$ \\
\hline & $\operatorname{reg} 8$ & Cataluña & $8.75 \%$ & $8.72 \%$ \\
\hline & reg9 & Comunidad Valenciana & $6.98 \%$ & $10.77 \%$ \\
\hline & reg10 & Extremadura & $3.63 \%$ & $3.38 \%$ \\
\hline & reg11 & Galicia & $6.77 \%$ & $8.60 \%$ \\
\hline & reg12 & Madrid & $9.67 \%$ & $8.40 \%$ \\
\hline & reg13 & Murcia & $6.81 \%$ & $3.95 \%$ \\
\hline & reg14 & Navarra & $2.57 \%$ & $2.59 \%$ \\
\hline & reg15 & Pais Vasco & $4.96 \%$ & $4.82 \%$ \\
\hline & reg16 & La Rioja & $3.10 \%$ & $1.82 \%$ \\
\hline
\end{tabular}

Table I.

Variables and descriptive statistics

Note: People in the age group of $16-64$ years

Source: EDADES 2007, 2013

Of the three types of consumption considered, and for both years, cannabis users show lower increases in their probability of being jobless. There is a rise of 3.4 percentage points (pp) for those who report using this substance in the past 12 months in 2007 (4.8 and 5.6 pp, respectively, for cocaine and cannabis + cocaine), with respect to non-users. The results obtained for 2013 reveal a significant increase in the difference of probability of being unemployed for drug users. Considering the indicator of consumption, the $A T T$ reaches a 
value of 8.64 pp., in the case of cannabis users; 9.73 pp among those who consume cocaine and $9.73 \mathrm{pp}$ for those who claim to have consumed both substances in the past year.

The results are similar with nearest-neighbour matching (Table IV). However, in contrast with the estimates used in Table III, a statistically significant effect cannot be detected in the estimates made for 2013 with the population that claims to have consumed either cocaine or both cannabis and cocaine simultaneously, in the past year.

A covariate imbalance test was used to gauge the quality of the results. Here, "balance" is defined as the similarity in the empirical distributions for the full set of covariates in the matched treated and control groups. It is checked by considering $t$-tests for equality of means in the treated and non-treated groups, and the standardised bias before and after matching. The $t$-values on post-matching samples and the percentage reduction on bias suggest that the matching was successful. Except for age and people living in the same home, none of the other variables in the treated group are statistically different from the nontreated group[1].

In Table AII (Appendix), additional quality indicators are presented. The pseudo- $R^{2}$ shows how well the regressors explain participation probability. A reduction in the pseudo- $R^{2}$ and the observed selection bias confirm that the quality of the matching estimations is good.

Table V shows the results for the impact of drug use on unemployment, using the DID method. In all the estimates, the $\gamma$ parameter indicates that the economic crisis intensified the negative effects of drug use on employment (the effect is higher for poly-drug users). We can conclude that drug consumption during an economic downturn intensified the negative effects on an individual"s employability.

\section{Conclusions}

The WHO is drawing attention to the substantial impact that the economic crisis is having on the population's mental health. People can be socially excluded because they have lower income levels and belong to marginal groups, as is the case with drug users (World Health Organization [WHO], 2011). A recent systematic review of literature (Silva et al., 2018) suggests that periods of economic crisis can be linked to an increase in general help sought for mental health problems, a higher use of prescription drugs and a greater number of hospital admissions for mental disorders.

This trend has been empirically tested in countries such as Greece, which were severely affected by the economic crisis (Kondilis et al., 2013). According to the data presented by the authors, suicide and homicide mortality rates increased by 22.7 per cent and 27.6 per cent, respectively between 2007 and 2009, and mental disorders and substance abuse morbidity showed downward trends during 2010 and 2011. Along the same lines, Medel-Herrero and Gomez-Beneyto (2019) identified that psychiatric hospital admissions sharply increased in 2008, coinciding with the outset of the

\begin{tabular}{lcccccc}
\hline & \multicolumn{2}{c}{ Cannabis use } & \multicolumn{2}{c}{ Cocaine use } & \multicolumn{2}{c}{ Cannabis and cocaine use } \\
Population & 2007 & 2013 & 2007 & 2013 & 2007 & 2013 \\
\hline Unemployed (\%) & 13.25 & 34.23 & 15.87 & 37.45 & 16.49 & 39.61 \\
Employed (\%) & 56.40 & 36.63 & 62.19 & 44.57 & 59.72 & 40.82
\end{tabular}

Source: EDADES 2007, 2013

Illegal drug consumption in Spain

161

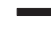


AEA

28,83

162
Table III.

Impact estimates of cannabis, cocaine and cannabiscocaine consumption on unemployment in 2007 and 2013.

Propensity score with Gaussian Kernel

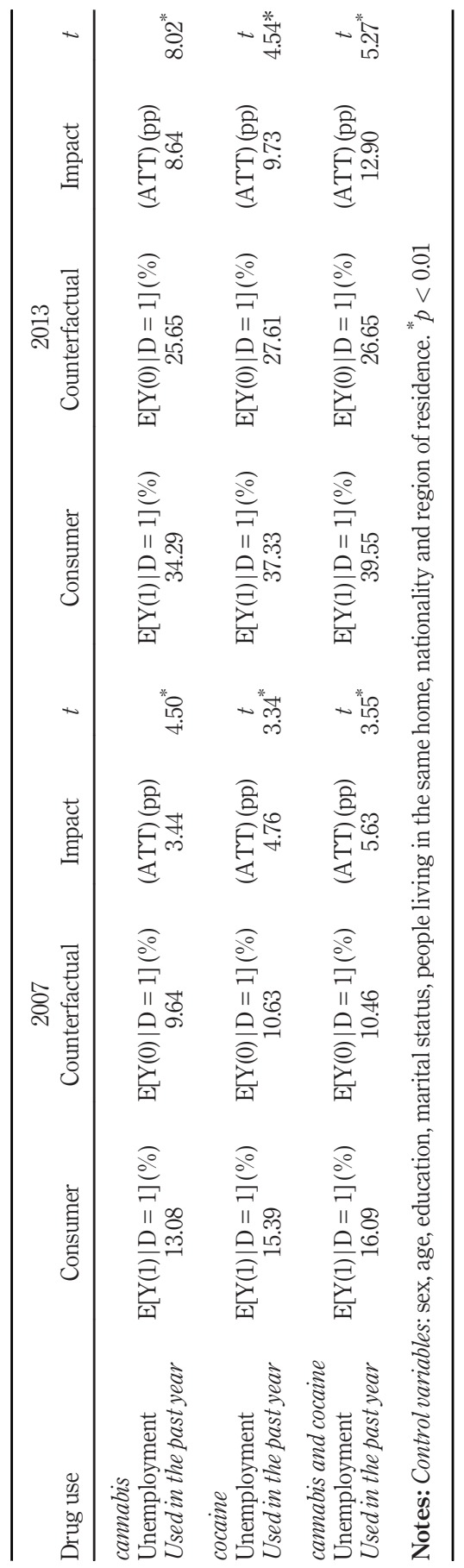




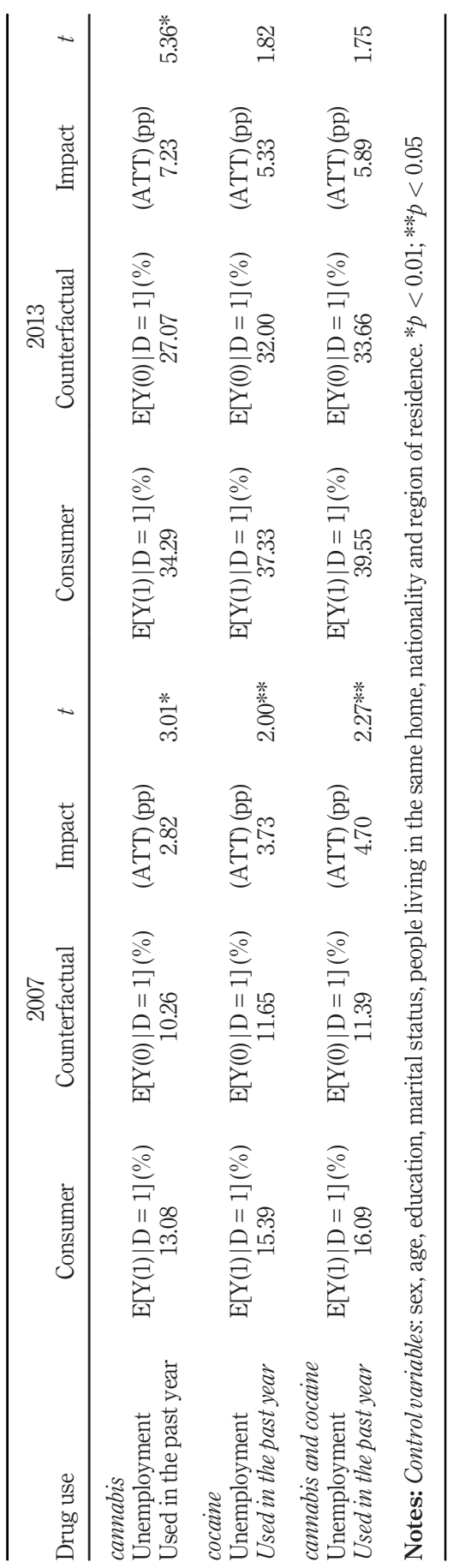

Illegal drug consumption in Spain

Table IV. Impact estimates: cannabis, cocaine and cannabiscocaine consumption on unemployment in 2007 and 2013. Propensity score with nearest neighbour 
AEA 28,83

164

economic crisis in Spain. These effects were particularly intense for the group of inpatients between 25 and 34 years old.

Different studies have analysed the relationship between macroeconomic employment conditions and drug consumption (Freeman, 1999; Dee, 2001; Ruhm and Black, 2002; Arkes, 2012; Dávalos et al., 2012; Harhay et al., 2013; Mattei et al., 2014; Colell et al., 2015). However, the results have been mixed and inconclusive, generating a great deal of debate regarding the mechanism and direction of the causality (Costa et al., 2011; European Monitoring Centre for Drugs, and Drug Addiction [EMCDDA], 2012; Dom et al., 2016).

The results obtained in the current study are consistent with the hypothesis that drug use decreases an individual's capacity and availability when he or she is trying to enter the labour market. In both 2007 and 2013, drug users were more likely to be unemployed, regardless of the type of drug. Differences in the probability of being unemployed intensify during an economic crisis. In light of these results, it is possible to conclude that the negative effect of drug consumption on an individual's employability is increased during periods of economic recession.

As mentioned earlier, there is wide empirical research supporting the negative effect of illicit drug use on unemployment (MacDonald and Pudney, 2000; French et al., 2001 and Alexandre and French, 2004). Specifically, for comparative purposes, our results coincide with the analysis carried out by Compton et al. (2014), which links unemployment and problematic substance use. With a similar approach to the one employed here, the analysis was done between the periods before and after an economic crisis in the USA. Using data from the 405,000 non-institutionalised adults, substance use was compared between unemployed and employed people. The results obtained from multivariate logistic regression models showed that employment status was robustly associated with the problematic use of substances.

The study presented here has some limitations. Firstly, cross-sectional data were used to examine the causal relationship between consumption and employment. In this sense, the results are susceptible to bias. The unavailability of longitudinal data on the same individual made it impossible for the researchers to consider periods of abstinence, the duration of periods of consumption and how this consumption affected an individual's productivity and his or her working situation.

Another limitation is that certain relevant unemployment variables may have been omitted. Among the variables that affect an individual's labour participation is the existence of sources of income as an alternative to market salaries. With state subsidies, income from

\begin{tabular}{|c|c|c|c|c|}
\hline Substance & Parameter & Coefficients $(95 \% \mathrm{CI})$ & R-squared & $n$ \\
\hline \multirow[t]{2}{*}{ Cannabis } & $\begin{array}{l}\lambda \\
\delta\end{array}$ & $\begin{array}{l}0.145^{*}(0.138 ; 0.152) \\
0.032^{*}(0.017 ; 0.046)\end{array}$ & \multirow[t]{2}{*}{0.08} & \multirow[t]{2}{*}{44,590} \\
\hline & $\gamma$ & $0.052^{*}(0.028 ; 0.077)$ & & \\
\hline \multirow[t]{2}{*}{ Cocaine } & $\begin{array}{l}\lambda \\
\delta\end{array}$ & $\begin{array}{r}0.149^{*}(0.142 ; 0.155) \\
0.031^{* *}(0.004 ; 0.059)\end{array}$ & \multirow[t]{2}{*}{0.08} & \multirow[t]{2}{*}{44,590} \\
\hline & $\gamma$ & $0.058^{* * *}(0.009 ; 0.107)$ & & \\
\hline \multirow[t]{2}{*}{ Cannabis and cocaine } & $\begin{array}{l}\lambda \\
\delta\end{array}$ & $\begin{array}{r}0.149^{*} \\
0.04^{*}(0.142 ; 0.155)\end{array}$ & \multirow[t]{2}{*}{0.08} & \multirow[t]{2}{*}{44,590} \\
\hline & $\gamma$ & $0.072^{* * *}(0.017 ; 0.128)$ & & \\
\hline
\end{tabular}

\section{Table V.}

DID estimates for the impact of use drugs on employment before and during the economic crisis
Notes: Model controlling for sex, age, education, marital status, people living in the same home, nationality and region of residence $\stackrel{*}{p}<0.01 ; \quad p<0.05$ 
illegal activities and money sent by family or friends, an individual may decide not to work. This problem could be mitigated if omitted variables operate in a similar way throughout both of the periods examined.

Nevertheless, the sources of income mentioned earlier, such as handouts from someone close to the individual, can diminish as a result of the economic crisis. Similarly, state subsidies may undergo severe budget cuts in austerity programmes, especially those related to spending on social welfare and health care. Thus, in the period under study, public spending has been dramatically reduced in programmes that integrate former drug users into society or back into work. This trend can have a negative impact on the likelihood of the reference population finding work.

In spite of these limitations, it can be argued that this study could make various contributions to the previously existing body of evidence. It is the first attempt to document the effect of the economic crisis on the employability of the drug-using population in contrast with the general population. Moreover, with the matching techniques used on the estimates carried out, a methodology is presented that provides an alternative to those used in earlier studies, in terms of reducing treatment-selection bias. In recent works, this empirical strategy has played a role in analysing the relationship between unemployment and health status variables (for example, UrbanosGarrido and Lopez-Valcarcel, 2015). At the same time, the use of a DID estimation method between pre- and current-crisis periods allow us to check if the impact of drugs consumption on unemployment depends on the economic context.

As a result of negative trends in the gross domestic product per capita during the period between 2007 and 2013, in Spain, the welfare state provided less financial assistance and coverage of public health interventions to drug use. A sharp reduction in the drug policy budget for Spain can be detected for this period: from $€ 463 \mathrm{~m}$ to $€ 367 \mathrm{~m}$. Services for drug users, such as reintegration and prevention programmes, have faced reductions in terms of the availability and quality of care [Delegación del Gobierno para el Plan Nacional sobre Drogas (DGPNSD), 2013].

Given the results obtained in this article, we believe that public policy conclusions should be mainly concerned with the importance of implementing proactive employment policies, along with family support programmes and a greater role for primary care among the people with the highest risks of exclusion. Health treatment should coincide with measures that make it easier for individuals to enter the workforce. These steps would only be possible with an improved level of education and more complete professional profiles, to increase motivation when individuals seek employment. Drug users are not a homogenous population in terms of what they want and need, or how susceptible they are to relapsing. For this reason, measures have to be adapted to the various sub-groups within this population.

In recent years, the resources allocated to training and integration into the job market have been seriously jeopardised in Spain [Delegación del Gobierno para el Plan Nacional sobre Drogas (DGPNSD), 2013]. With such elevated unemployment rates and a job market that is increasingly competitive in terms of training and qualifications, illegal drug users have to receive better training, as well as learn how to improve their job seeking skills.

\section{Note}

1. Covariance balance results are available upon request. 
Alexandre, P.K. and French, M.T. (2004), "Further evidence on the labour market effects of addiction: chronic drug use and employment in metropolitan Miami”, Contemporary Economic Policy, Vol. 22 No. 3, pp. 382-393.

Arkes, J. (2012), "How does youth cigarette use respond to weak economic periods? Implications for the current economic crisis", Substance Use and Misuse, Vol. 47 No. 4, pp. 375-382.

Arroyo, E., Cabrera-León, A., Renart, G., Saurina, C., Saurina, L.S., Daponte, A. and Saez, M. (2019), "Did psychotropic drug consumption increase during the 2008 financial crisis? A cross-sectional population-based study in Spain”, British Medical Journal Open, Vol. 9 No. 1.

Artazcoz, L., Benach, J., Borrell, C. and Cortes, I. (2004), "Unemployment and mental health: understanding the interactions among gender, family roles, and social class", American Journal of Public Health, Vol. 94 No. 1, pp. 82-88.

Ayllón, S. and Ferreira-Batista, N.N. (2018), "Unemployment, drugs and attitudes among European youth”, Journal of Health Economics, Vol. 57, pp. 236-248.

Böckerman, P. and Ilmakunnas, P. (2009), "Unemployment and self-assessed health: evidence from panel data", Health Economics, Vol. 18 No. 2, pp. 161-179.

Buchmueller, T.C. and Zuvekas, S.H. (1998), "Drug use, drug abuse, and labour market outcomes", Health Economics, Vol. 7 No. 3, pp. 229-245.

Caliendo, M. and Kopeinig, S. (2008), "Some practical guidance for the implementation of propensity score matching", Journal of Economic Surveys, Vol. 22 No. 1, pp. 31-72.

Chang, S.S., Gunnell, D.L., Steme, J.A., Lu, T.H. and Cheng, A.T. (2009), "Was the economic crisis 19971998 responsible for rising suicide rates in East/Southeast Asia? A time-trend analysis for Japan, Hong Kong, South Korea, Taiwan, Singapore and Thailand”, Social Science and Medicine, Vol. 68 No. 7, pp. 1322-1331.

Colell, E., Sánchez, -Niubò, A., Delclos, J.L., Benavides, F.G. and Domingo-Salvany, A. (2015), "Economic crisis and changes in drug use in the Spanish economically active population", Addiction, Vol. 110 No. 7, pp. 1129-1137.

Compton, W.M., Gfroerer, J., Conway, K.P. and Finger, M.S. (2014), "Unemployment and substance outcomes in the United States 2002-2010", Drug and Alcohol Dependence, Vol. 142, pp. 350-353.

Costa, C., De Grauwe, P., Sabadash, A. and Montanari, L. (2011), "Unemployment and drug treatment", International Journal of Drug Policy, Vol. 22 No. 5, pp. 366-373.

Dávalos, M.E., Fang, H. and French, M.T. (2012), "Easing the pain of an economic downturn: macroeconomic conditions and excessive alcohol consumption", Health Economics, Vol. 21 No. 11, pp. 1318-1335.

De Goeij, M., Suhrcke, M., Toffolutti, V., Van de Mheen, D., Schoenmakers, T.M. and Kunst, A.E. (2015), "How economic crisis affect alcohol consumption and alcohol-related health problems: a realist systematic review", Social Science and Medicine, Vol. 131, pp. 131-1456.

Dee, T.S. (2001), "Alcohol abuse and economic conditions: evidence from repeated cross-sections of individual-level data", Health Economics, Vol. 10 No. 3, pp. 257-270.

Delegación del Gobierno para el Plan Nacional sobre Drogas [DGPNSD] (2013), Memoria Del Plan Nacional Sobre Drogas, Ministerio de Sanidad, Servicios Sociales e Igualdad, Madrid.

Delegación del Gobierno para el Plan Nacional sobre Drogas [DGPNSD] (2015), Memoria Del Plan Nacional Sobre Drogas, Servicios Sociales e Igualdad, Madrid: Ministerio de Sanidad.

Dom, G., Samochowiec, J., Evans-Lacko, S., Wahlbeck, K., Van Hal, F. and McDaid, D. (2016), "The impact of the 2008 economic crisis on substance use patterns in the countries of the European union", International Journal of Environmental Research and Public Health, Vol. 13 No. 1, p. 122. 
Dubanowicz, A. and Lemmens, P. (2015), "Impact of the economic recession on addiction-pone behaviours", in Anderson, P. Rehm, J. and Room, R. (Eds), The Impact of Addictive Substances and Behaviours on Individual and Societal Well-Being, Oxford University Press, Oxford.

Economou, A., Nikolaou, A. and Theodossiou, I. (2008), "Are recessions harmful to health after all? Evidence from the European union”, Journal of Economic Studies, Vol. 35 No. 5, pp. 368-384.

European Monitoring Centre for Drugs and Drug Addiction [EMCDDA] (2009), Polidrug Use: patterns and Response, Publications Office of the European Union, Luxembourg.

European Monitoring Centre for Drugs, and Drug Addiction [EMCDDA] (2012), Annual report 2012: The state of the drug problem in Europe, Publications Office of the European Union, Luxemburg.

Freeman, D.G. (1999), "A note on economic conditions and alcohol problems", Journal of Health Economics, Vol. 18 No. 5, pp. 661-670.

French, M.T., Roebuck, M.C. and Kebreau, P. (2001), "Illicit drug use, employment, and labour force participation", Southern Economic Journal, Vol. 68 No. 2, pp. 349-368.

Gill, A.M. and Michaels, R.J. (1992), "Does drug use lower wages?", Industrial and Labor Relations Review, Vol. 45 No. 3, pp. 419-434.

Harhay, M.O., Bor, J., Basu, S., McKee, M., Mindell, J.S., Shelton, N.J. and Stuckler, D. (2013), "Differential impact of the economic recession on alcohol use among white British adults, 20042010”, European Journal of Public Health, Vol. 24 No. 3, pp. 410-415.

Henkel, D. (2011), “Unemployment and substance use: a review of the literature (1990-2010)”, Current Drug Abuse Reviews, Vol. 4 No. 1, pp. 4-27.

Instituto Nacional de Estadística [INE] (2014), Encuesta de Población Activa, INE, Madrid.

Jenkins, R., Bhugra, D., Bebbington, P., Brugha, T., Farrell, M., Coid, J., Fryers, T., Weich, S., Singleton, N. and Meltzer, H. (2008), "Debt, income and mental disorder in the general population", Psychological Medicine, Vol. 38 No. 10, pp. 1485-1493.

Kaestner, R. (1991), "The effect of illicit drug use on the wages of young adults", Journal of Labor Economics, Vol. 9 No. 4, pp. 381-412.

Khan, S., Murray, R. and Barnes, G. (2002), "A structural equation model of the effect of poverty and unemployment on alcohol abuse", Addictive Behaviors, Vol. 27 No. 3, pp. 405-423.

Kondilis, E., Giannakopoulos, S., Gavana, M., Ierodiakonou, I., Waitzkin, H. and Benos, A. (2013), "Economic crisis, restrictive policies, and the population's health and health care: the Greek case”, American Journal of Public Health, Vol. 103 No. 6, pp. 973-979.

MacDonald, Z. and Pudney, S. (2000), "Illicit drug use, unemployment, and occupational attainment", Journal of Health Economics, Vol. 19 No. 6, pp. 1089-1115.

Marmot, M.G. and Bell, R. (2009), "How will the financial crisis affect health?", BMJ, Vol. 338 No. apr01 3, p. b1314.

Martín, N. and Vall, J. (2016), "Effects of the great recession on drugs consumption in Spain”, Economics and Human Biology, Vol. 22, pp. 103-116.

Mathers, C.D. and Schofield, D.J. (1998), "The health consequences of unemployment: the evidence", Medical Journal of Australia, Vol. 168 No. 4, pp. 178-182.

Mattei, G., Ferrari, S., Pingani, L. and Rigatelli, M. (2014), "Short-term effects of the 2008 great recession on the health of the Italian population: an ecological study", Social Psychiatry and Psychiatric Epidemiology, Vol. 49 No. 6, pp. 851-858.

Medel-Herrero, A. and Gomez-Beneyto, M. (2019), "The impact of 2008 economic crisis on the increasing number of young psychiatric inpatients", Revista de Psiquiatria y Salud Mental (English Edition), Vol. 12 No. 1, pp. 28-36.

Nagelhout, G.E., Hummel, K., de Goeij, M., de Vries, H., Kaner, E. and Lemmens, P. (2017), "How economic recessions and unemployment affect illegal drug use: a systematic realist literature review", International Journal of Drug Policy, Vol. 44, pp. 69-83. 
AEA 28,83

Observatorio Español sobre Drogas [OED] (2007), Encuesta Domiciliaria Sobre Alcohol y Drogas en España (EDADES), 1995-2007, Delegación del Gobierno para el Plan Nacional sobre Drogas, Ministerio Del Interior, Madrid.

Observatorio Español sobre Drogas [OED] (2013), Encuesta Domiciliaria Sobre Alcohol y Otras Drogas en España (EDADES), 1995-2013, Delegación del Gobierno para el Plan Nacional sobre Drogas, Ministerio Del Interior, Madrid.

Register, C.A. and Williams, D.R. (1992), "Labour market effects of marijuana and cocaine use among young men", Industrial and Labor Relations Review, Vol. 45 No. 3, pp. 435-448.

Ritter, A. and Chalmers, J. (2011), "The relationship between economic conditions and substance use and harm", Drug and Alcohol Review, Vol. 30 No. 1, pp. 1-3.

Ruhm, C.J. and Black, W.E. (2002), "Does drinking really decrease in bad times?”, Journal of Health Economics, Vol. 21 No. 4, pp. 659-678.

Silva, M., Resurrección, D.M., Antunes, A., Frasquilho, D. and Cardoso, G. (2018), "Impact of economic crises on mental health care: a systematic review".

Skapinakis, P., Weich, S., Lewis, G., Singleton, N. and Araya, R. (2006), "Socio-economic position and common mental disorders. Longitudinal study in the general population in the UK", British Journal of Psychiatry, Vol. 189 No. 2, pp. 109-117.

Stata Corp (2015), Stata Statistical Software: Release 14, Stata Corp LP, College Station, TX.

Stuckler, D., Basu, S., Suhrcke, M., Coutts, A. and McKee, M. (2011), "Effects of the 2008 recession on health: a first look at European data", The Lancet, Vol. 378 No. 9786, pp. 124-125.

Urbanos-Garrido, R. and Lopez-Valcarcel, B. (2015), "The influence of the economic crisis on the association between unemployment and health: an empirical analysis for Spain", The European Journal of Health Economics, Vol. 16 No. 2, pp. 175-184.

Van Hal, G. (2015), "The true cost of the economic crisis on psychological well-being: a review”, Journal of Psychology Research and Behavior Management, Vol. 8, pp. 17-25.

Van Ours, J.C. (2006), “Cannabis, cocaine and jobs”, Journal of Applied Econometrics, Vol. 21 No. 7, pp. 897-917.

Wilkinson, R. and Marmot, M. (Eds) (2003), Social Determinants of Health: The Solid Facts, 2nd ed., WHO Regional Office for Europe, Copenhagen.

World Health Organization [WHO] (2009), Financial Crisis and Global Health: report of a High-Level Consultation, World Health Organization, Geneva.

World Health Organization [WHO] (2011), Impact of Economic Crises on Mental Health, World Health Organization, Geneva.

\section{Further reading}

Leuven, E. and Sianesi, B. (2003), "PSMATCH2: Stata module to perform full Mahalanobis and propensity score matching, common support graphing, and covariate imbalance testing", Version 4.0. 11. Research Papers in Economics.

\section{Corresponding author}

Berta Rivera can be contacted at: berta@udc.es 


\title{
Appendix
}

\author{
Illegal drug \\ consumption \\ in Spain
}

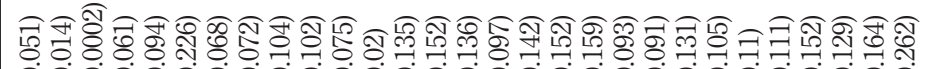

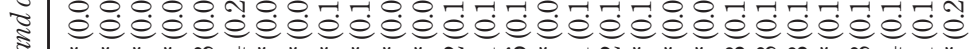

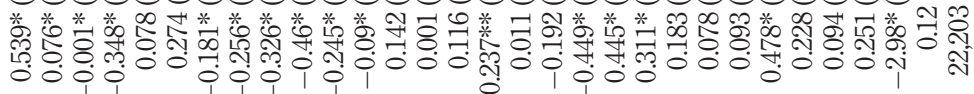

芯 :

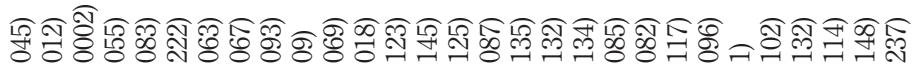

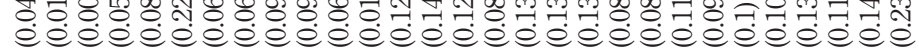

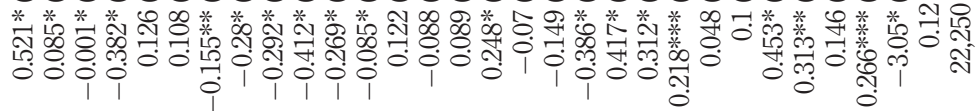

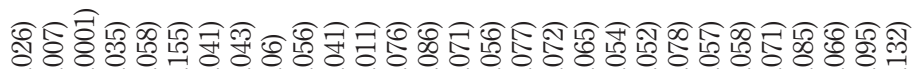

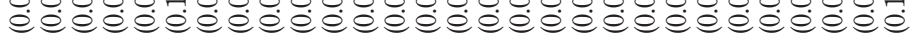

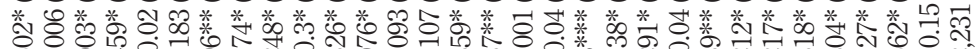

药

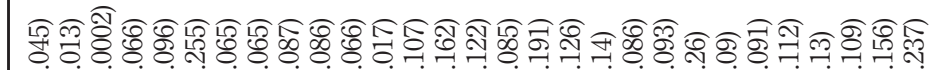

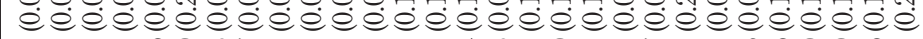

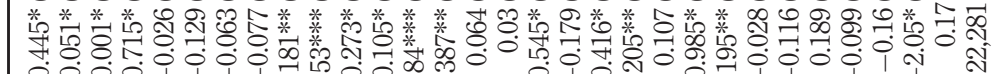

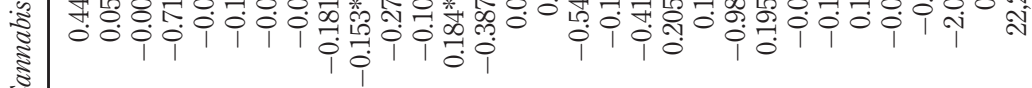

है

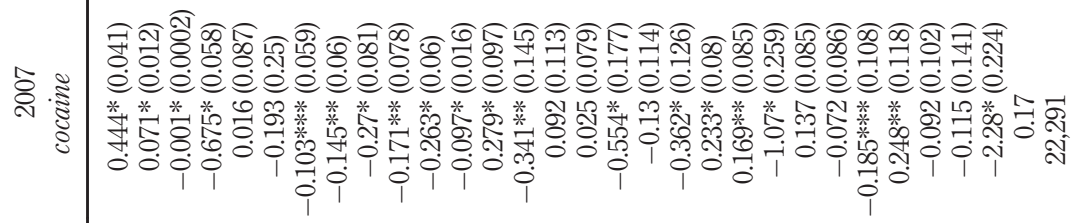

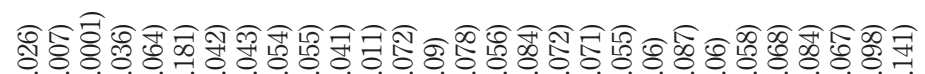

है

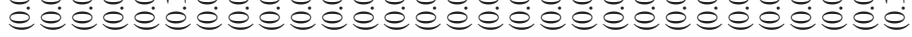

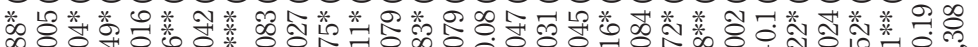

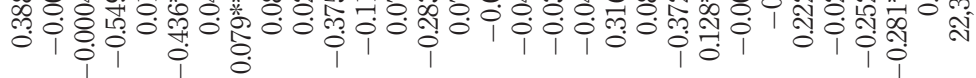

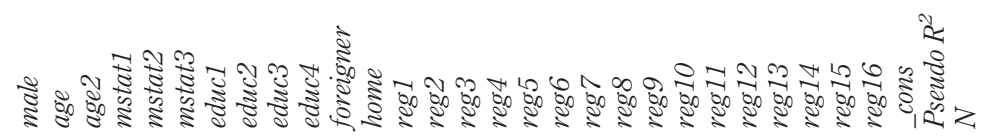

Table AI.

Probit models of

drug use 
AEA

28,83

170

Table AII.

Absolute bias,

pseudo- $\mathrm{R}^{2}$ and LR chi $^{2}$

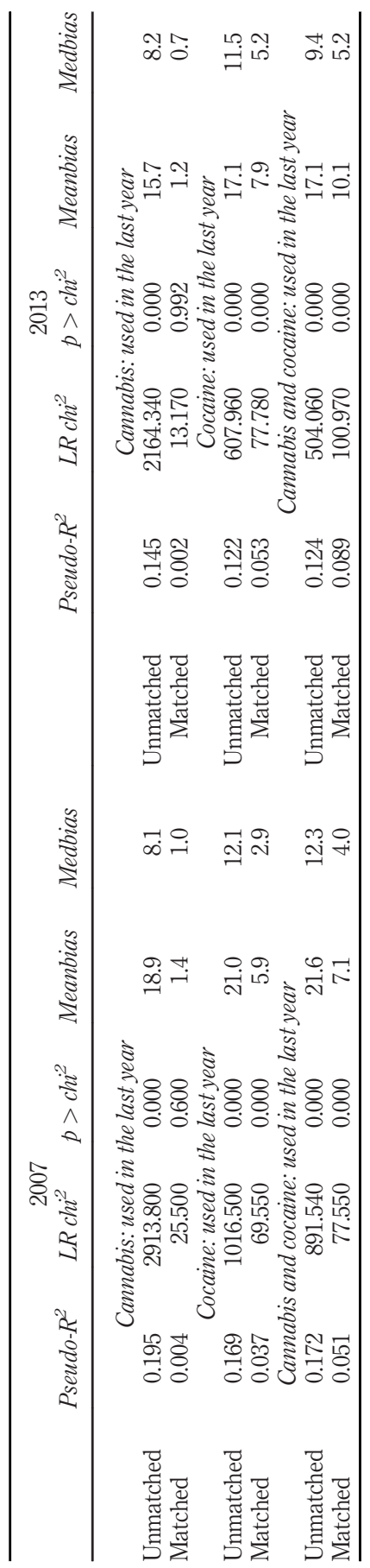

